\title{
Changes in sperm surfaces associated with epididymal transit
}

\author{
R. H. Hammerstedt and J. E. Parks* \\ Program in Biochemistry, The Pennsylvania State University, University Park, PA 16802, and \\ *Department of Animal Science, Cornell University, Ithaca, NY 14853, U.S.A.
}

\section{Introduction}

The paucity of progress towards understanding the functions of the individual gamete membrane systems in terms of their molecular structures is highlighted by the limited data base currently available. This is due in part to those factors that limit all studies of membrane structure-function: our understanding of two-phase chemical systems is quite primitive and assays for specific functional features of membranes are difficult to devise and validate. Superimposed on these general limits are the unique features of the sperm-oocyte system. Currently, it appears that while gametes from various species share a common endpoint (fusion of the haploid cells) they may differ in the molecular details and/or timing of events leading to this fusion. Care must therefore be taken to avoid overgeneralizations with regard to the data obtained from the few systems that have been studied in depth.

With respect to the topic of this specific symposium, the literature review and synthesis of common features of epididymal sperm membrane changes in the domestic ruminants (bull and ram) could be terse, as very limited data are available. Since a truncated presentation limited to reported membrane changes would be of minimal value, we have chosen to supplement the presentation by: (1) expanding the topic to include a more general description of types of molecular questions that should be considered for more rapid progress in this research area; (2) providing examples of apparent conflicts among reported results to reinforce the fact that different methods used to study the same phenomenon may yield different interpretations (at least until the methods themselves are completely understood); and (3) creating an honorary ruminant (the pig) to illustrate the detailed studies that are possible in an animal of great economic interest. The literature included in this review encompasses the period of 1980-1986, with a few references to earlier data in order to assemble the desired model. The interested reader would greatly benefit from review articles prepared by others and listed in Table 1 .

Alteration of the sperm surface certainly occurs at all points of cellular transit from the testis through to penetration of the oocyte. A complete description of the role of the efferent, epididymal and deferent ducts is, therefore, necessary. Ruminant models for these studies will be most useful because of the large numbers of cells available from a single animal and the ability to cannulate the various portions of the male reproductive tract (see comparisons in Hammerstedt, 1981). Studies utilizing the ruminant are less frequent than those of rodents and most current concepts of the requirements for important biological events (e.g. the acrosome reaction and capacitation) stem from studies using spermatozoa from the cauda epididymidis. Such studies neglect the role of the accessory sex gland fluids on sperm function.

A systematic comparison of the features of cauda epididymal and ejaculated spermatozoa has been made in this laboratory, demonstrating important differences in sperm motility (Inskeep et al., 1985), metabolism (Hammerstedt, 1981; Inskeep \& Hammerstedt, 1982; Inskeep et al., 1985) and membrane features (Hammerstedt et al., 1976, 1979a, b, 1982). Use of data from studies utilizing cauda epididymal spermatozoa to predict molecular mechanisms for true physiological events are viewed as suspect. Such considerations argue for an increased use of species (ruminant, pig or rabbit) from which ejaculates can be easily obtained for studies of those events related to processing within the female reproductive tract. 
Table 1. Recent reviews of sperm surface changes as related to epididymal transit

\begin{tabular}{ll}
\hline Topic emphasized & \multicolumn{1}{c}{ Reference } \\
\hline Carbohydrate determinants & Ahuja (1985) \\
Immunochemical characterization & Eddy et al. (1985) \\
Post-testicular sperm maturation of the boar & Crabo (1985) \\
Domains of sperm membranes & Koehler (1985) \\
General sperm surface aspects & Austin (1985) \\
Sperm membrane antigens & O'Rand (1985) \\
Overview of membrane features & Fraser (1984) \\
Sperm membrane features, with an emphasis on development of function & Holt (1982) \\
General sperm surface changes & Olson \& Orgebin-Crist (1982) \\
General discussion of the sperm surface, with emphasis on the mouse & Koehler (1982) \\
General discussion of the sperm surface & Nicolson (1982) \\
Ultrastructural and cytochemical analysis of sperm membranes & Fléchon (1981) \\
\hline
\end{tabular}

\section{Molecular considerations in membrane modification}

The surface of the sperm cell must be viewed from at least two perspectives in order to appreciate the complexity of the system. The first perspective is one based on microscopic considerations and the second is based on deductions from chemical and physical analyses. These considerations allow comment on interpretation of membrane changes and experimental design.

\section{The microscopic perspective}

Similarities in the general organization of the spermatozoon from various species (Fig. 1) are apparent, and functions can be related to the distinct zones of the cell, e.g. motility to the tail, flux of metabolic substrates and end products to the middle-piece, oocyte binding and penetration to the anterior head. Existing data further enhance the concept of an organized and specialized surface in that heterogeneous distributions of proteins (Eddy et al., 1985) and lipids (Wolf \& Voglmayr, 1984; Schlegel et al., 1986) have been described.

Two experimental approaches are required to determine the significance of such heterogeneity. The first would seek to establish the relationship between chemical features of one of the unique surface regions and the function(s) of that region. This requires a carefully validated assay for the function of interest, plus the ability to isolate experimentally the membrane components and complete the necessary chemical analysis of the isolate. Results of several analyses of isolated membrane components from the surface region overlying the acrosome have recently been published (Parks \& Hammerstedt, 1985; Nikolopoulou et al., 1985) but these data have not yet provided an explanation for the unique function(s) of that surface region. The second type of experiment characterizes the membrane features that allow heterogeneous surfaces to be formed and persist during extended periods of sperm transit through and storage within the male tract (Peterson \& Russell, 1985). While the existence of such macromolecular domains is evident, available data do not satisfactorily describe any mode of accomplishing this segregation. One possibility is establishment of anchors, i.e. restriction of movement via interaction of surface components with integral membrane components and/or cytoplasmic components that bind to internal membrane surface. The second would be via formation of collars - as yet unidentified membrane-membrane junctions that define zones of heterogeneity. Implicit in either of these or any other mechanism is the requirement for continuous energy input to maintain a state of non-equilibrium. However, conventional wisdom assigns the ATP-generating systems to the middle-piece (see Mann \& Lutwak-Mann, 1981) and mechanisms to transfer ATP to distant regions of the cell, e.g. the anterior head, have yet to be proposed. 


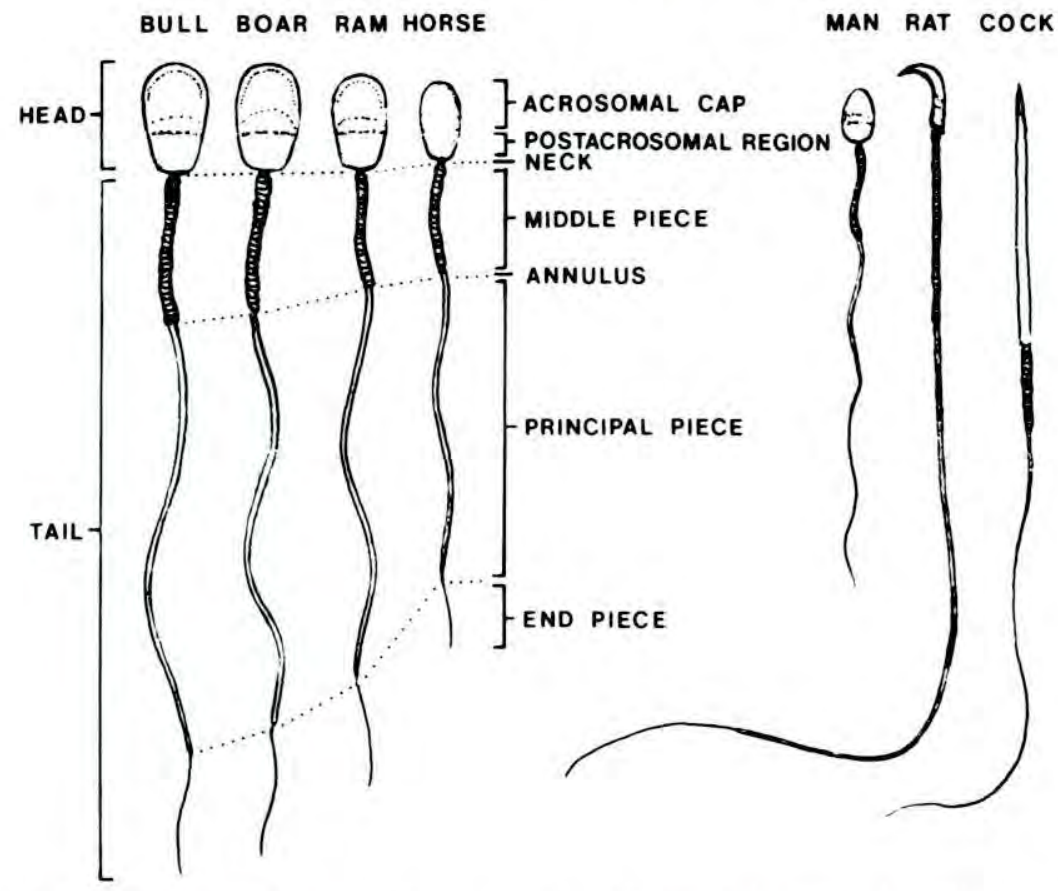

Fig. 1. Representative drawings of spermatozoa from various species, illustrating the general similarities with regard to the zones of the cell surface, i.e. anterior and posterior head, middle-piece and tail. Taken from p. 168 of $\mathrm{Hafez}(1980)$.

\section{The submicroscopic perspective}

The second perspective is one based on submicroscopic detail (Fig. 2). In this case studies are guided by rapidly evolving concepts of membrane structure as deduced from studies (reviewed in a series edited by Benga, 1985) of model membrane systems and selected cellular systems (e.g. the erythrocyte). Cytoplasmic domains, lipid bilayer integral components (both protein and lipid), lipid-water interfaces, protrusions of bilayer components into extracellular water and adsorbed components all interact to yield the functional unit of any surface zone.

Membrane modification is not trivial for any cell type, and the sperm cell probably has fewer options available than most cells because of its limited biosynthetic capacity for both lipids and proteins. To a first approximation this limits the possibilities to: (1) exchange of components between interior membrane components and the surface membranes; (2) lateral movement of components from one zone of the surface to another (within the restrictions imposed by anchors and collars); and (3) exchange of components between the surrounding milieu (epididymal lumen, seminal plasma, uterine and oviducal fluids) and the sperm surface. Addition or deletion of components from within the cell probably can occur via a minimally complex mechanism because the cytoplasm and inner surface of the membrane are contiguous. Transfer of lipid, for example, might only require a lipid transfer protein of the type found in many different somatic cells (reviewed by Wirtz, 1982; Helmkamp, 1983; Zilversmit, 1983). Transfer between spermatozoa and extracellular fluids requires an external approach to the bilayer surface and can be accomplished only after passage through a variety of extracellular components.

Any component destined to be moved to the cell and inserted as an integral membrane protein must display the solubilities, at the appropriate time, for both the aqueous fluids and the non-polar bilayer. Polar features are inherent in basic protein structure, but special post-translational modifications might be necessary for the non-polar aspects. Recent descriptions of events occurring in 


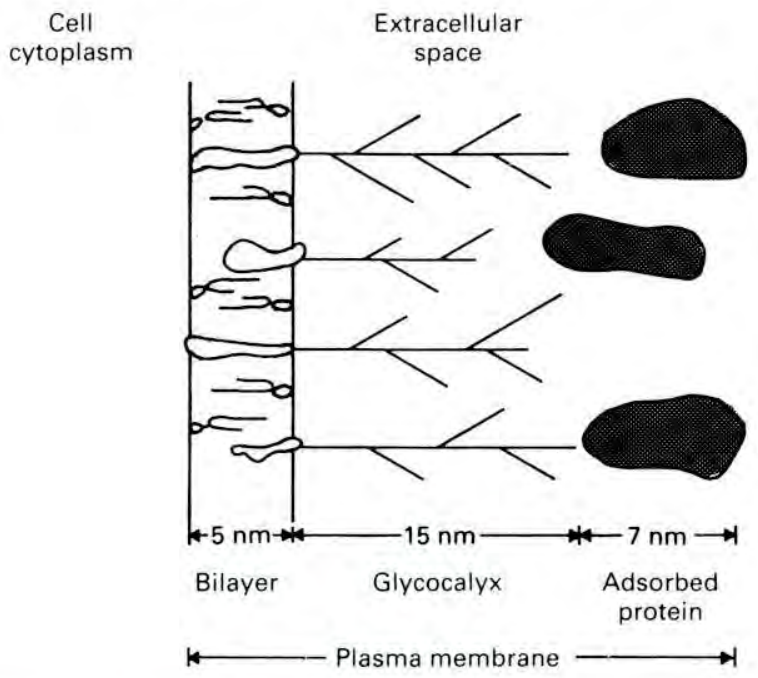

Fig. 2. Schematic representation of the plasma membrane, showing the scale of the bilayer and the types of molecules that could be associated with the exterior face of the membrane. It is important to note that the plasma membrane consists of much more than the bilayer.

somatic cell systems provide models for such complex post-translational modifications. One possibility is fatty acylation (Wold, 1986) whereby fatty acyl residues are added to the basic protein structure to yield a molecule with high affinity for the membrane. A second possibility is derivatization by transfer of phosphatidylinositol (Low et al., 1986). This mechanism could be especially important in view of the changes in free inositol content of the epididymal lumen that have been described by others (reviewed by Amann, 1987), since the role of inositol in sperm maturation remains an enigma.

\section{Interpretation of membrane changes}

Empirical observations of the disappearance and appearance of membrane components are useful, but must ultimately be interpreted in terms of the membrane location relative to the bilayer (see Fig. 2). It is useful to remember that appearance may be due to addition to the most exterior aspect of the surface (adsorbed components) or unmasking of previously masked (to the test reagent) sites. Disappearance can be due to complete removal of the component or masking of the determinant of interest via addition of another moiety. To date no study has described mechanisms at this level.

\section{Relationship to experimental design}

Selected biological events may be uniquely dependent upon those aspects of the membrane displayed in Fig. 2. For example, acquisition by spermatozoa of the ability to bind to the oocyte may be related to an alteration of molecular features of the outermost aspects of the surface. In contrast, the fusion of plasma and outer acrosomal membrane during the acrosome reaction may be dependent on the molecular features of the inner surfaces of the plasma membrane network. Such considerations are necessary to the design of experiments to study these very different but related events in sperm-oocyte fusion. 


\section{Analysis of apparently contradictory results}

Techniques usually are developed in model systems and then are applied to the study of more complex biological systems. Often, as information accumulates, it becomes apparent that the earlier interpretations must be carefully re-evaluated. Two examples of this, evaluation of membrane fluidity and analysis of lectin binding data, are presented below to illustrate the effect of choice of method on the perception of membrane characteristics.

\section{Membrane fluidity}

The difficulties of defining, much less measuring, membrane fluidity have been discussed in detail by others (see Lands, 1980). In a single phase and chemically defined medium the definition is simple and often is taken as the reciprocal of the measured viscosity; as such the viscosity can be evaluated by classical hydrodynamic techniques. For more complex systems, particularly biological membranes, greater care must be taken to define explicitly the desired feature. Current awareness of general membrane structure has introduced the consideration of motion in any of the three dimensions of the membrane surface; rotations perpendicular to the surface plane, lateral movement along the surface plane, and movement through the plane. Careful definition of the type of motion measured in each experiment must be given.

Another aspect that must be considered is the time scale of the measurement, since various spectroscopic techniques (nuclear magnetic resonance $v s$ electron paramagnetic resonance) evaluated motional parameters on very different time scales. Usually, the latter methods involve adding trace amounts of spectroscopically detectable compounds to the cell, allowing them to bind to and segregate into the various lipid-containing domains and evaluating the distribution of the compound. Then conclusions can be reached, via comparisons to other systems that have been studied, with regard to the freedom of motion of the trace component in the membrane.

Results from three different studies of ram spermatozoa, as a function of epididymal transit, are compared to illustrate different types of conclusions that can be reached using different techniques.

Evaluation by relative packing density of a membrane probe. Schlegel et al. (1986) utilized the impermeable fluorescent membrane probe merocyanine 540 (MC540), which displays preferential binding to loosely packed phospholipids in model membranes, to assess changes in distribution and packing of lipids of the sperm surface as a function of epididymal maturation. Differential binding was noted, with the most intense fluorescence associated with the posterior portion of the sperm head and the middle-piece. This is consistent with the conclusion that these portions of the surface are loosely packed relative to other portions of the surface, i.e. these zones are more fluid. Since the probe cannot penetrate the bilayer, results gathered using this technique reflect the properties of the outer half of the plasma membrane layer. It is also important to note that this is a static method whereby dye partitioning is allowed to come to equilibrium and then the distribution of dye is subjectively evaluated by visual examination with the fluorescence microscope. No difference in dye distributions was detected for ram spermatozoa as a function of epididymal transit although differences were found for mouse spermatozoa. These results led to the conclusion that the lipid packing at the outer face of the bilayer (believed to be directly related to fluidity) differs across the various surface domains of the ram spermatozoa, but does not change during sperm maturation within the epididymis.

Evaluation by diffusion coefficient of a membrane probe. Wolf \& Voglmayr (1984) used a different technique to evaluate motional properties in the membrane surface. An impermeable carbocyanine dye $(\mathrm{Cl} 16 \mathrm{diI})$ that partitions into the outer half of the bilayer of the plasma membrane was used and the partitioning of the dye was evaluated by visual comparison of the fluorescence patterns and also quantified by the technique of fluorescence recovery after photobleaching. This combination of measurements allows a comparison of the quantity of dye in any surface region (by the visual estimate) and the motional properties of the dye molecule in the plane of the membrane 
(by measurement of the diffusion constant using the photobleaching technique). A similar distribution pattern to that reported by Schlegel et al. (1986) was described. Comparison of testicular spermatozoa (those cells that have been released from the testis but have not been exposed to the epididymal environment) and ejaculated spermatozoa (complete epididymal maturation plus mixture with the accessory sex gland fluids) revealed differences in the estimated diffusion constant for C16diI. Specifically, all zones of the sperm surface except that of the middle-piece were altered to yield an environment where the dye had an increased diffusion constant; movements in the plane of the membrane surface occurred more rapidly. Wolf et al. (1986) have reported other results for the motional properties of membrane proteins in ram spermatozoa.

Evaluation by partition coefficient of a membrane probe. In contrast to the above techniques, which utilize intact spermatozoa and microscopic evaluation, selective membrane removal by cavitation treatment yields a preparation of membrane vesicles derived from the plasma membrane overlying the anterior portion of the sperm head. Such preparations have been analysed for changes in membrane composition (Parks \& Hammerstedt, 1985) and now are available for analysis by appropriate spectroscopic techniques.

Electron paramagnetic resonance spectroscopy can be used to analyse the motional properties of nitroxyl spin probes in the membrane (see Hammerstedt et al., 1976, for an overview of the application of the technique to sperm systems). Detailed evaluations of motional properties of such spin probes in a variety of membrane preparations have been presented and extensively analysed (Keith et al., 1973; Marsh, 1981; Schwartz, 1982; Hemminga, 1984; Devaux \& Seigneuret, 1985), but a detailed consideration (see Polnaszek et al., 1978) has clearly outlined some of the pitfalls inherent in these interpretations. Results of a more restricted analysis are presented herein.

Systematic changes in the structure of the spin probe yields a series of compounds with different partition coefficients between the aqueous phase of a membrane vesicle suspension and the lipid phase of that system. This partitioning can be assessed by the spectroscopic features of the preparation, and the change in partitioning, as a function of temperature, can be readily assessed (Fig. 3). The spin probe 5-doxyldecane (Molecular Probes, Inc., Junction City, OR), at a ratio of

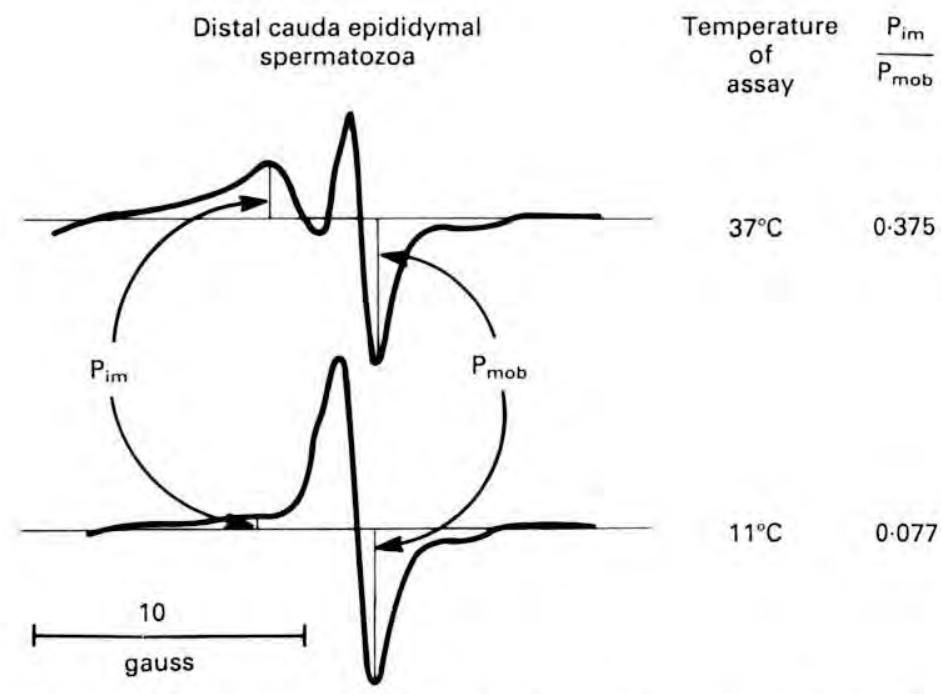

Fig. 3. Sample electron paramagnetic resonance spectra of the nitroxyl spin label 5-doxyldecane in a sperm membrane preparation. The high-field line of the spectrum for 5-doxyldecane in a ram sperm plasma membrane vesicle suspension at two temperatures is shown. The change in partitioning associated with temperature is reflected in the ratio of immobilized $\left(\mathrm{P}_{\mathrm{im}}\right)$ and freely mobile $\left(\mathrm{P}_{\mathrm{mob}}\right)$ aspects of the spectroscopic signal. These two peaks are proportional to the amount of 5-doxyldecane in the membrane lipid and in bulk water. 


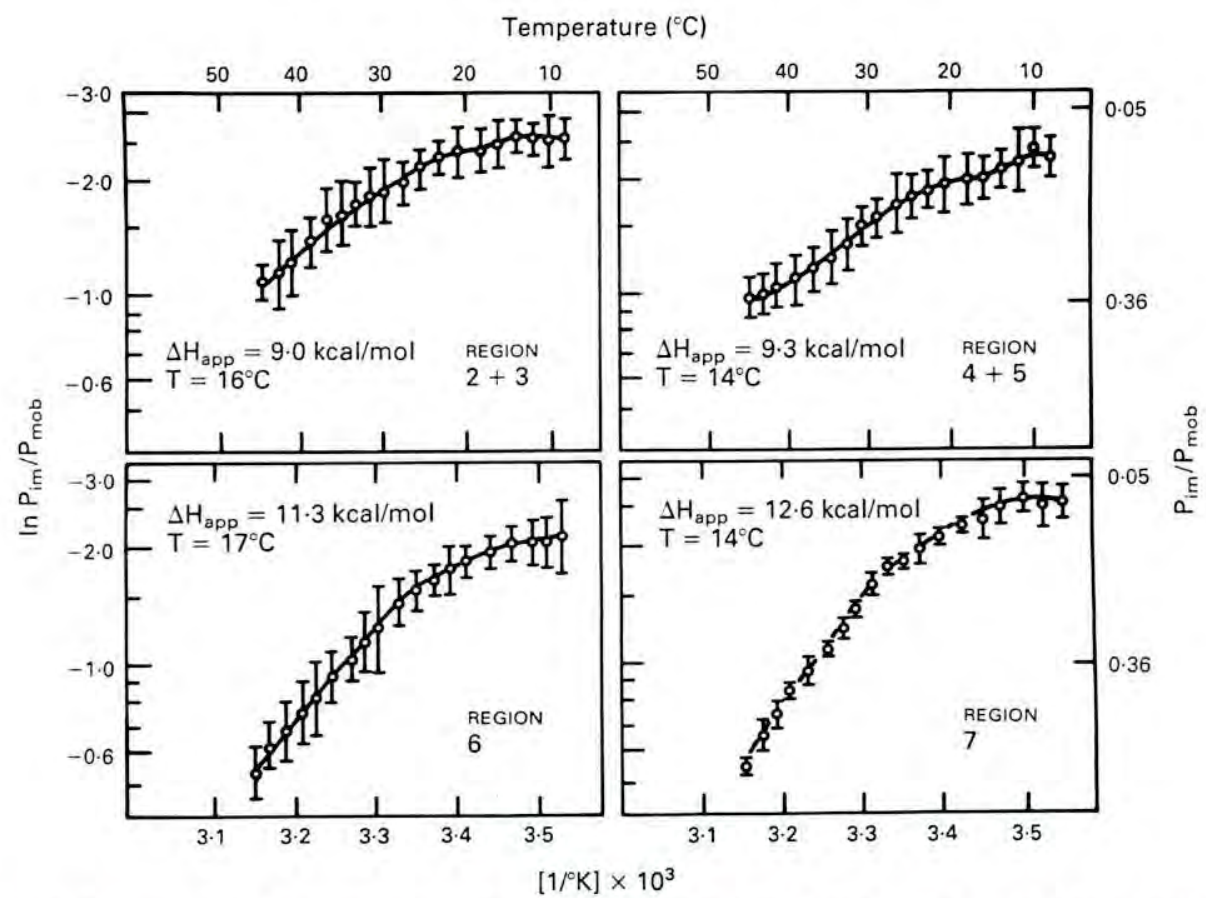

Fig. 4. Changes in the partitioning of the spin label 5-doxyldecane into plasma membrane vesicles of the anterior zone of ram spermatozoa. Sperm membrane preparations were isolated as described by Parks \& Hammerstedt (1985) and the partitioning of 5-doxyldecane calculated as outlined in Fig. 3. Membrane vesicles were isolated from spermatozoa from the caput (Region $2+3$ ), corpus (Region $4+5$ ), proximal cauda (Region 6) and distal cauda plus vas deferens (Region 7). These correspond to the regions M2, M3a, F1 and F2 as defined by Amann (1987). The data for each region are presented in the form of an Arrhenius plot, with an estimate via computer analysis (Jones \& Molitoris, 1984) of the temperature dependence of the partitioning $(\mathrm{m})$ and apparent phase transition temperature $(\mathrm{T})$. The values for the apparent enthalpy change $\left(\Delta \mathrm{H}_{\mathrm{app}}\right)$ (as estimated for the data between 20 and $45^{\circ} \mathrm{C}$ ) increases with transit through the epididymis while no significant change was noted for the range of 8 to $20^{\circ} \mathrm{C}$. The points represent the mean \pm s.e.m. for 4 complete replicates.

$20 \mathrm{nmol}$ spin label per $150 \mathrm{nmol}$ membrane phospholipid, yielded appropriate partitioning for analysis of ram sperm membrane vesicles. The spectral component labelled $\mathrm{P}_{\mathrm{im}}$ relates to the relatively immobilized component (dissolved in the membrane) while the component $P_{\text {mob }}$ relates to the spin label residing in bulk water. An Arrhenius plot $\left[\left(\ln \mathrm{P}_{\mathrm{im}} / \mathrm{P}_{\mathrm{mob}}\right)\right.$ vs $\left.(1 / \mathrm{K})\right]$ will yield a single straight line if temperature-induced changes in solubility of the spin label in lipid relative to that of water are not abruptly altered by changes in the lipid vesicle (i.e. by lipid phase changes). Changes in the slope of the line, as a function of temperature, reflect changes in the ability of the lipid phase to dissolve spin label and have generally been interpreted to mean changes in the bulk fluidity of the preparation. This refers to an average fluidity of total bilayer lipid and is not directly related to any specific surface distribution of the lipid.

Changes in this measure of fluidity were observed in vesicles isolated from ram spermatozoa (Fig. 4). The slight changes in apparent transition temperature $\left(14-17^{\circ} \mathrm{C}\right)$ probably are not significant but the increased percentage of 5-doxyldecane that partitions into the membrane and the increased apparent enthalpy change $\left(\Delta \mathrm{H}_{\mathrm{app}}\right)$ are striking and reflect an abrupt change in membranes isolated from cells after transit into the proximal portion of the cauda epididymidis. To a 
Fig. 5.

Con A

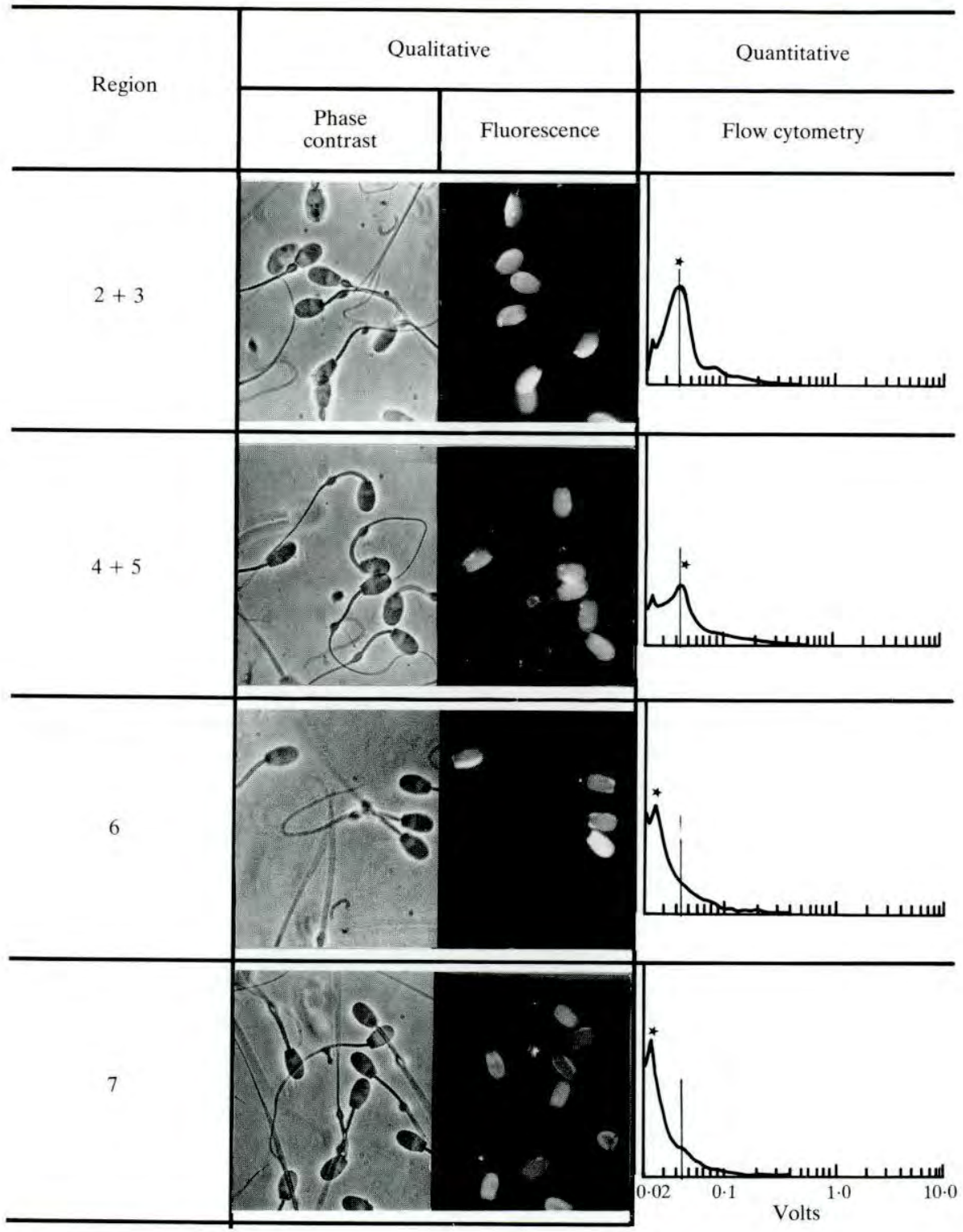


first approximation the plasma membrane overlying the acrosome becomes more fluid during epididymal transit, perhaps due to the large increase in the degree of unsaturation in the acyl groups of the phospholipids (Parks \& Hammerstedt, 1985). Since the ability to fertilize ova is acquired at this same point in epididymal transit, a preliminary conclusion might be that the increase in fluidity is related to this aspect of membrane function.

A further extension of these data (not presented) to include comparison of membranes from cauda epididymal spermatozoa to those of ejaculated spermatozoa revealed the surprising result that the membranes of ejaculated spermatozoa changed in their fluidity features to resemble those of caput epididymal spermatozoa. This calls in to question the preliminary conclusion above that bulk membrane fluidity is uniquely related to some sperm membrane function, such as its ability to undergo an acrosome reaction. Interpretation of these latter changes awaits completion of the chemical analyses, but supports our earlier contention that extrapolation of data from cauda epididymal to ejaculated spermatozoa may be misleading. It is also important to remember that the effects of uterine and/or oviducal fluids on the membranes have yet to be evaluated.

\section{Use of lectins to evaluate surface glycosyl residues}

Lectins, a group of plant and invertebrate proteins that interact with carbohydrate components, can be used as probes for changes in the surface features of spermatozoa. Concanavalin A (con A) detects changes in ram spermatozoa in glycosyl residues (highest specificity for alpha mannosyl residues) associated with epididymal transit. With reference to Fig. 2, these reagents would be used to detect the appearance and disappearance of the determinant on all aspects of the exterior surface (glycolipid at the bilayer surface, glycoproteins of glycocalyx or adsorbed protein) that are accessible to the lectin.

Evaluation by lectin-induced agglutination. Hammerstedt et al. (1982) utilized the bivalent features of con A to induce a specific agglutination of cell suspensions. A careful titration was conducted to establish a lectin to sperm ratio that allowed specific agglutination (a head-to-tail pattern that was blocked by addition of an inhibitory sugar) to be evaluated for all sperm cell types tested. They concluded that caput spermatozoa agglutinated readily, corpus spermatozoa agglutinated to a lesser extent, and that the agglutination property was restored for cauda spermatozoa.

Evaluation by saturation analysis. Fournier-Delpech \& Courot (1980) have studied lectin binding by caput, corpus and cauda epididymal ram spermatozoa and reached a different conclusion. Isotopically labelled con A and saturation or Scatchard plots were used to quantitate the number of binding sites per sperm cell; a decrease in sites per cell was detected. These reports further establish, using lectin affinity columns, that the molecular nature of the surface components changes during transit.

Fig. 5. Representative examples of FITC-con A binding to ram spermatozoa. Spermatozoa from regions of the epididymis (as defined in Fig. 4) were analysed for the distribution of lectin over the various zones of the sperm surface by microscopy (phase contrast and epifluorescence; left panel) and amount of lectin bound by the cell analyser (right panel). The photographs were taken under conditions where the optimum image for each field was recorded. This results in a valid comparison of intensities within each field (i.e. zones of the spermatozoa in that field) but does not yield valid information across fields (i.e. comparison of spermatozoa at different stages of maturation). Such quantitative comparisons are evident in the right panel where the gain of the amplifier was adjusted so that unstained cells do not appear on the output. The entire distribution (presented on a log scale) therefore illustrates the range of staining intensities but not the percentage of cells that were stained. This representative trace $(>20000$ cells evaluated per sample) illustrates the decrease in staining intensity for spermatozoa isolated from the various regions of the same epididymis. An equivalent trend was seen in 5 other replicates. 
The apparent contrast in conclusions from these studies and those of Hammerstedt et al. (1982) may be due to one of several factors. The first relates to the host of surface features that can influence the ability of a lectin to agglutinate cell suspensions. They include: (1) the total number of saccharide binding sites per cell; (2) binding constants of different sites for the same lectin; (3) the number of lectin-saccharide interactions that are needed for cell-cell agglutination; (4) mobility of lectin 'receptors' in the membrane; (5) interference of other cell-surface components; (6) net charge on the glycocalyx; and (7) possible influence of cytoskeletal elements. A second possibility resides in the fact that it has been very difficult to establish whether lectin binding follows the necessary quantitative features for Scatchard analysis. Susko-Parrish et al. (1985) carefully tested the binding features of isotopically labelled succinylated con A to ejaculated bull spermatozoa. This con A derivative is monovalent and allows the optimum opportunity to study binding without the complicating effects of agglutination. They concluded that the binding kinetics were too complex to allow any estimate of number of binding sites per cell for this cell type. If these conditions apply to ram epididymal spermatozoa, the apparent contradiction may be explained. The observance by Fournier-Delpech \& Courot (1980) of differences in the molecular nature of the components isolated by lectin affinity columns still remains as strong evidence for alteration in the cell surface associated with epididymal transit.

Evaluation by flow cytometry. In an attempt to circumvent the above problems in quantitating the number of lectin binding sites per cell, we (S. Magargee, E. Kunze \& R. H. Hammerstedt, unpublished observations) have adopted a different means of analysis. Fluorescently labelled con A distribution over the surface of ram spermatozoa was evaluated by microscopic analysis to assess the zones of the surface that were labelled (i.e. head $v s$ tail). The amount of lectin bound to the cells was also quantified by passing the suspension through an Epics V flow cytometer (Coulter Electronics, Inc., Miami, FL, U.S.A.). A series of initial experiments tested a wide range of lectin to sperm ratios to establish conditions in which no cell type (caput, corpus or cauda) was saturated. This fixed ratio was used to test all cell types because discrimination in extent of binding is possible when all assays are tested under these subsaturating conditions.

Representative data (Fig. 5) for con A binding are presented. The left panel presents the distribution over the cell surface, where lectin is predominantly associated with the entire head but not the middle piece or tail of the spermatozoa at all stages of development. The right panel presents a quantitative evaluation of the amount of lectin per cell, as detected by the cell analyser. The population is somewhat heterogeneous, with a progressive decrease in fluorescence intensity noted as spermatozoa traverse the epididymis.

\section{Recent studies in sperm surface changes associated with epididymal maturation}

Results of recent efforts to examine changes on the sperm surface as a function of epididymal maturation have been assimilated, by species, into Tables $2-4$. These reports are primarily descriptive in nature and have been categorized according to the type of membrane component(s) that were modified during epididymal transit. Changes in proteins therefore include modifications in the quantity and distribution of integral membrane proteins, adsorption or modification of proteins from testicular and epididymal fluids and changes in the specific activity of membrane associated enzymes. Carbohydrate changes refer to modifications in the carbohydrate moieties of glycoproteins and glycolipids initially part of the sperm surface as well as changes mediated by interaction with epididymal fluid components. Reports of modifications in sperm membrane lipids include changes in composition of the major classes of sperm plasma membrane lipids (phospholipids, sterols and phospholipid-bound fatty acyl chains) as well as the resulting physical changes in the sperm surface.

It is apparent that information on surface modifications to bull spermatozoa during epididymal maturation is very limited (Table 2). The ram may prove to be a very useful ruminant model for the 
Table 2. Recent reports of sperm surface changes of bulls as related to epididymal transit and ejaculation*

PROTEINS

$\dagger 1$. Identification of ${ }^{125} \mathrm{I}$-labelled surface proteins of $M_{\mathrm{r}} 16000-100000$ on proximal caput spermatozoa by SDS-PAGE; loss of components of $M_{\mathrm{r}} 15000-18000$ in distal cauda with decrease in components of $M_{\mathrm{r}}$ $90000-100000$ and increase in those of $M_{\mathrm{r}} 42000-47000$ (Vierula \& Rajaniemi, 1981, 1982).

$\dagger$. Protein methylesterase activity 20 -fold higher in caput than cauda spermatozoa (Gagnon et al., 1984).

†3. Adenylate cyclase activity 4 -fold greater in caput than cauda spermatozoa (Casillas et al., 1980).

†4. Forward motility protein binds to caput spermatozoa (Acott \& Hoskins, 1981).

$¥ 5$. Identification of antigenic determinants on washed, ejaculated spermatozoa by indirect immunofluorescence of monoclonal antibodies, not present on testicular or epididymal spermatozoa (Chakraborty, 1983).

\section{CARBOHYDRATES}

$\$ 1$. No difference in con A binding in acrosomal or post-acrosomal region between caput and cauda spermatozoa using colloidal gold technique; decreased con A binding on flagellum of cauda spermatozoa; no change in WGA binding except for increased intensity in distal, post-acrosomal region (Sinowatz \& Friess, 1983; Friess \& Sinowatz, 1984).

$\$ 2$. Decreased binding of rhodamine-conjugates of con A and WGA over acrosomal and post-acrosomal regions between caput and cauda; decrease in WGA but not con A binding to flagellum; increase in PNA binding in acrosomal region between caput and cauda (Arya \& Vanha-Perttula, 1985).

$\uparrow$ 3. Epididymal fluid $\beta-N$-acetylglucosaminidase activity increased between caput and cauda; bound to epididymal spermatozoa (Jauhiainen \& Vanha-Perttula, 1986).

1. No reports

LIPIDS

*Report describes an alteration that directly or indirectly affects the indicated component. Carbohydrate refers to changes in glycoprotein or glycolipid.

$\dagger$ Alteration detected via chemical or physical analysis.

†Alteration detected via microscopic analysis.

Table 3. Recent reports of sperm surface changes of rams as related to epididymal transit and ejaculation*

\section{PROTEINS}

†1. Identification of ${ }^{125} \mathrm{I}$-labelled surface proteins of $M_{\mathrm{r}} 78000-132000$ on testicular spermatozoa by 2-dimensional SDS agarose PAGE; lost by entry into proximal caput where components of $M_{\mathrm{r}} 17000-65000$ appear; little change from distal caput to proximal cauda where components of $M_{\mathrm{r}} 4000,65000$ and 97000 become prominent and protein of $M_{\mathrm{r}} 24000$ appears; no direct relationship established between changes in fluid proteins and sperm surface proteins, although testicular spermatozoa adsorbed protein of $M_{\mathrm{r}} 24000$ from cauda fluid; many components identified as glycoproteins; some radioactivity from both integral and adsorbed proteins inaccessible to trypsin, suggesting internalization (Voglmayr et al., 1980, 1982; Dacheux \& Voglmayr, 1983).

†2. Detection of surface protein of $M_{\mathrm{r}} 90000$ accessible to ${ }^{125} \mathrm{I}$-labelling on proximal caput spermatozoa by SDSPAGE; appearance of additional proteins of $M_{\mathrm{r}} 24000,33000,45000$ and 67000 on distal cauda spermatozoa (Vierula \& Rajaniemi, 1982).

†3. Surface proteins (from $M_{\mathrm{r}} 13500-145000$ ) of testicular spermatozoa ${ }^{125} \mathrm{I}$-labelled and analysed by SDS-PAGE; proteins of $M_{\mathrm{r}} 72000-88000$ lost in proximal caput, protein of $M_{\mathrm{r}} 17500$ lost in proximal corpus and proteins of $M_{\mathrm{r}} 108000-115000$ lost in distal corpus; component of $M_{\mathrm{r}} 145000$ appeared in caput and components of $M_{\mathrm{r}}$ 13500 and 66000 appeared in corpus (Dacheux et al., 1985).

\$4. Distribution of colloidal gold-labelled corpus fluid proteins found over anterior head of testicular spermatozoa, entire head of corpus spermatozoa, and posterior head except for the equatorial segment of cauda spermatozoa (Courtens et al., 1982).

$\$_{+}^{+5}$. Partial purification of a polymorphic antagglutinin from cauda fluid; reversed autoagglutination of corpus spermatozoa (Dacheux et al., 1983).

†6. Activity of myo-inositol-1-phosphate synthase 3-fold higher in caput than corpus or cauda spermatozoa (Loewus et al., 1983).

†7. Plasma membrane $\mathrm{Ca}^{2+}$-ATPase activity 3-fold higher in ejaculated than cauda spermatozoa; 3-fold activation of enzyme in cauda spermatozoa by seminal protein calsemin (Bradley \& Forrester, 1981).

\section{CARBOHYDRATES}

+1 . Identification of surface glycoproteins of $M_{\mathrm{r}} 98000$ and 102000 on testicular spermatozoa by galactose oxidase$\mathrm{NaBH}_{4}$ and 2-dimensional SDS agarose-PAGE; retained in cauda spermatozoa with addition of components of $M_{\mathrm{r}} 24000,35000$ and 350000 ; loss of glycoproteins of $M_{\mathrm{r}} 24000$ and 35000 from ejaculated spermatozoa with 


\section{Table 3-continued}

component of $M_{\mathrm{r}} 350000$ very prominent; identification of surface sialoglycoproteins of $M_{\mathrm{r}} 79000,98000$ and 102000 on testicular spermatozoa by $\mathrm{NaIO}_{4}-\mathrm{NaBH}_{4}$; not present on cauda or ejaculated spermatozoa where sialylated components of $M_{\mathrm{r}} 15000$ and 48000 appear (Voglmayr et al., 1983).

†2. Identification of surface glycoproteins of $M_{\mathrm{r}} 26000-600000$ on testicular spermatozoa as above; only components of $M_{\mathrm{r}} 280000-600000$ were detected upon transit into the proximal corpus; glycoproteins of $M_{\mathrm{r}}$ $350000-600000$ very prominent in ejaculated spermatozoa where components of $M_{\mathrm{r}} 95000$ and 97000 appear; similar pattern after neuraminidase treatment plus appearance of components of $M_{\mathrm{r}} 24000-97000$ on cauda and ejaculated spermatozoa; surface sialoglycoproteins distributed similarly on testicular spermatozoa with fewer components of $M_{\mathrm{r}} 90000-155000$; loss of components of $M_{\mathrm{r}} 280000-600000$ by proximal corpus with appearance of sialoglycoproteins of $M_{\mathrm{r}} 24000-36000$ on cauda and ejaculated spermatozoa (Voglmayr et al., 1985).

†3. Identification of ${ }^{125} \mathrm{I}$-labelled surface glycoproteins with affinity for con A by con A-agarose followed by acrylamide-agarose chromatography; major component of $M_{\mathrm{r}} 110000$ and minor components of $M_{\mathrm{r}}<20000$ on corpus and cauda but not testicular spermatozoa; ${ }^{3} \mathrm{H}$-acetyl-con A binding sites on distal corpus spermatozoa only $25 \%$ of those on mid-corpus with no further decline on cauda spermatozoa (Fournier-Delpech \& Courot, 1980).

$\dagger+4$. Identification of surface glycoproteins of $M_{\mathrm{r}} 71000$ and 117000 with con A and WGA affinity as above; one distributed over acrosomal region of testicular spermatozoa but not present in corpus; one first appeared over post-acrosomal region in mid-corpus (Fournier-Delpech et al., 1984).

$\$ 5$. Corpus fluid glycoprotein with affinity for con A bound to acrosomal region of testicular but not cauda spermatozoa, detected using a colloidal gold technique (Courtens et al., 1982).

$\ddagger 6$. Head-to-head and head-to-tail agglutination of spermatozoa induced with RCA and UEA, head-to-tail with con A and WGA; degree of agglutination with RCA and UEA decreased between caput and corpus; con A agglutination was lower for corpus than caput or cauda spermatozoa; WGA agglutination increased between caput and cauda; FITC-con A distributed over entire sperm surface throughout the epididymis, but lectin bound per cell decreased based on cell fluorescence analysis (Hammerstedt et al., 1982; S. Magargee, E. Kunze \& R. H. Hammerstedt, unpublished results discussed in text).

$\$ \ddagger 7$. Negative surface charge assessed by quantitative analysis of colloidal iron hydroxide binding; binding much greater over surface of cauda spermatozoa; increase in negative charge almost entirely due to sialic acid residues, as assessed by neuraminidase treatment (Holt, 1980).

†8. Isoelectric focussing $\mathrm{pH}$ of $5 \cdot 2-5 \cdot 4$ found for testicular and proximal caput spermatozoa, $5 \cdot 0$ for central caput, 4.7-5.0 for distal cauda spermatozoa and 4.8 for ejaculated spermatozoa (Hammerstedt, 1979; Hammerstedt $e t$ al., 1979b, 1982).

¥9. Testicular spermatozoa did not bind cumulus-free rat oocytes; $50 \%$ of oocytes bound by mid-corpus spermatozoa; all oocytes bound by cauda spermatozoa with $>25$ spermatozoa/oocyte; spermatozoa intact and bound to unpenetrated zona by plasma membrane over acrosomal region (Fournier-Delpech et al., 1983).

$\dagger 1$. Comprehensive lipid analysis of plasma membrane overlying acrosome via HPLC and GLC; changes between caput and cauda spermatozoa included decrease in desmosterol to cholesterol ratio; increase in cholesterol to phospholipid ratio; high choline plasmalogen content with increase in choline to ethanolamine phosphatide ratio; increase in ratio of phospholipid-bound C22:6/C16:0, C22:6 was major acyl component of phosphatidylcholine (Parks \& Hammerstedt, 1985).

$\dagger$ †. Diffusion coefficient of membrane lipid analogue C16dil determined for sperm plasma membrane by fluorescence recovery after photobleaching; coefficient highest in midpiece, intermediate in head and lowest in flagellum of testicular and ejaculated spermatozoa; coefficient was greater for ejaculated than testicular spermatozoa in all surface regions except midpiece, indicating increased membrane fluidity (Wolf \& Voglmayr, 1984).

†3. Based on EPR measurements of surface directed spin labels, negative charge density increased between testicular and cauda spermatozoa and between cauda and ejaculated spermatozoa (Hammerstedt et al., 1979b).

†4. Partitioning of lipid-directed spin labels into sperm plasma membrane vesicles was evaluated for membranes recovered from the anterior portion of the head, overlying the acrosome (Hall \& R. H. Hammerstedt, unpublished results described in text).

†5. Partitioning of the impermeable membrane probe MC540 was evaluated for epididymal spermatozoa; no differences were detected over epididymal transit (Schlegel et al., 1986).

†6. Analysis of goat spermatozoa; activities of sperm phospholipase(s) A and lysophospholipase were 4-fold higher in caput spermatozoa than cauda spermatozoa; phosphatidyl-ethanolamine, -choline, -inositol and phosphatidic acid were hydrolysable by sperm phospholipase; lysophospholipase activity was 10-fold higher than phospholipase in caput and cauda spermatozoa (Atreja \& Anand, 1985).

*Report describes an alteration that directly or indirectly affects the indicated component. Carbohydrate refers to changes in glycoprotein or glycolipid.

†Alteration detected via chemical or physical analysis.

¥Alteration detected via microscopic analysis. 
Table 4. Recent reports of sperm surface changes in boars as related to epididymal transit and ejaculation*

PROTEINS

$\dagger$ 1. Comprehensive analysis of cauda epididymal and ejaculated sperm plasma membrane proteins and proteins of epididymal and individual accessory gland fluids by 2-dimensional SDS-PAGE with Coomassie blue and silver staining; no major differences in caput and cauda plasma membrane proteins; proteins of $M_{\mathrm{r}} 16000$ and 24000 only major components common to epididymal fluid; acquisition and loss of several minor proteins between caput and cauda; major plasma membrane proteins of $M_{\mathrm{r}} 14-20000,110000,115000$ and 300000 added by seminal plasma (Russell et al., 1984).

$\uparrow 2$. Identification of ${ }^{125} \mathrm{I}$-labelled surface proteins of $M_{\mathrm{r}} 13000-170000$ on testicular spermatozoa by 2-dimensional SDS-PAGE; loss of components of $M_{\mathrm{r}} 33000$ and $72-80000$ in proximal caput, in caput, and of 17000 and 108000 by distal corpus; appearance of proteins of $M_{\mathrm{r}} 13500$ and 145000 in caput (Dacheux et al., 1984).

†3. No distinct changes in ${ }^{125} \mathrm{I}$-labelled surface proteins detected by SDS-PAGE during epididymal maturation (Vierula \& Rajaniemi, 1982).

†4. Purified cauda fluid glycoprotein of $M_{\mathrm{r}} 133000$ first detected by immunofluorescence on elongating spermatids; over entire surface of testicular spermatozoa, most intense in post-acrosomal region; marked decrease in intensity by proximal corpus; comparable results with X-ray dispersion analysis using ferritin-conjugated antibody (Bostwick et al., 1980).

$\dagger+5$. Integral plasma membrane proteins of $M_{\mathrm{r}} 44000$ and 47000 common to caput and cauda spermatozoa; ELSIA endpoints at 50 -fold greater dilution of monoclonal antibody using cauda vs caput spermatozoa as antigen; indirect immunofluorescence indicated increased distribution and intensity of fluorescence in cauda spermatozoa and cauda epithelial secretory cells; possibly secreted by epididymis and inserted into bilayer during maturation (Peterson et al., 1985).

¥6. Dramatic shifts in localization of monoclonal antibodies against cauda sperm plasma membrane on surface of caput and cauda spermatozoa, based on indirect immunofluorescence; localization on flagellum and midpiece of caput spermatozoa, mid-piece on cauda spermatozoa and head on ejaculated spermatozoa; related to acquisition and loss of proteins from epididymal fluid and seminal plasma (Saxena et al., 1984).

$\dagger \ddagger$ 7. Partial purification of a polymorphic antagglutinin from epididymal fluid; reversed autoagglutination of corpus spermatozoa; normal decrease in agglutination in distal corpus corresponded to increased binding to zona-free hamster oocytes (Dacheux et al., 1983).

¥8. Freeze-fracture replicas demonstrated no distinct pattern of integral membrane proteins in proximal caput spermatozoa; domains with parallel arrays over acrosome and rectilinear arrays around neck and connecting piece in caput; hexagonal arrays around margin of head in distal corpus extend to post-acrosomal region in cauda, with most not detected in ejaculated spermatozoa (Suzuki, 1981).

$\dagger+9$. Sperm plasma membrane proteins of $M_{\mathrm{r}} 30000,45000$ and 70000 with high affinity for dextran sulphate and zona pellucida; present in cauda but not caput spermatozoa; cauda but not caput spermatozoa proteins blocked sperm-zona binding; antibodies to cauda spermatozoa blocked sperm-zona binding, were absorbed by cauda but not caput membrane vesicles (Peterson et al., 1986).

LIPIDS

†1. Comprehensive analysis of caput, corpus and cauda sperm plasma membrane via t.l.c. and g.l.c.; decrease in free fatty acids, major glycolipid, cholesterol and cholesterol to phospholipid ratio from caput to cauda spermatozoa, but increase in diacylglycerols, desmosterol and cholesterol sulphate; decrease in phosphatidyl-ethanolamine, -serine and -inositol; increase in phosphatidylcholine, sphingomyelin and phosphoinositides; high choline and ethanolamine plasmalogen content throughout; increase in C22:5 and decrease in $\mathrm{C16:0}$ in phosphatidyl-choline and -ethanolamine acyl components (Nikopoulou et al., 1985).

* Report describes an alteration that directly or indirectly affects the indicated component.

$\dagger$ Alteration detected via chemical or physical analysis.

$\ddagger$ Alteration detected via microscopic analysis.

study of epididymal sperm maturation because of its large testes and epididymides (and therefore sperm reserves) relative to body size. Changes in plasma membrane components of ram spermatozoa accessible to surface labels for proteins, glycoproteins, and sialoglycoproteins as well as lipid composition of plasma membrane from the region overlying the acrosome have been studied in detail (Table 3). Physical and compositional changes related to surface charge density and membrane fluidity also have been measured in epididymal ram spermatozoa. To date, none of these changes have been directly related to any aspect of sperm function. 
The boar has been included as an honorary ruminant because of the elegant and detailed analyses (Table 4) of both the polypeptide and lipid composition which have been conducted on a defined and functionally important region of the plasma membrane, that overlying the acrosome. In addition, changes in specific polypeptides have been directly related to the acquisition of oocyte binding ability of this species.

\section{Conclusion}

This review has focussed on recent reports that describe changes in the sperm surface associated with epididymal transit. Since concepts of membrane structure are evolving rapidly, it is suggested that original interpretations of data should be carefully re-evaluated. This is especially true when different methods are used to evaluate the membrane system.

In the first case selected for study, changes in membrane fluidity associated with epididymal transit, the methods sample different aspects of the membrane surface and/or have different sensitivities for detection of changes. The apparently conflicting conclusions may, therefore, be resolved by careful definition of the membrane features actually sampled by the probes used in the experiments. Simply stated, different methods sampling different aspects of the bilayer may yield different observations. In the second case, changes in glycosyl residues that react with con A, alterations have been detected and quantitated by independent methods. Insensitive methods cannot detect slight changes, but application of recently developed techniques that quantitatively evaluate individual cells does provide the sensitivity and precision necessary to evaluate cells. In all cases, molecular mechanisms to account for these changes have yet to be proposed.

Finally, little progress in the study of sperm membrane structure-function relationships will be made without careful attention to the results of experiments utilizing membranes of other, more highly studied, biological systems. A further cataloguing of changes will be of little value, and design of experiments without detailed considerations of the interrelated features of the plasma membrane (Fig. 2) will only lead to ambiguity when the results are finally integrated into a general hypothesis regarding membrane function. It is especially important that new techniques be adopted or adapted for evaluating membrane function as related to sperm maturation. Progress in other membrane systems has been more rapid and models for the necessary general methods and overall experimental design are available (see Racker, 1985). Similar progress in this area will require: (1) in-vitro models for the events assumed essential (e.g. ion flux, specific vesiculation, membrane-membrane binding); (2) development of procedures for the isolation of specific membrane components; and (3) reconstitution of the system(s) for molecular analysis. Both the challenge and the required effort to accomplish these goals will be great, but so will be the satisfaction derived from finally gaining an understanding of any aspect of the molecular basis of gamete fusion.

Financial support was provided by NIH-NICHD-13099 (to R.H.H.) and NIH-NICHD-18628 (to J.E.P.).

\section{References}

Acott, T.S. \& Hoskins, D.D. (1981) Bovine sperm forward motility protein: Binding to epididymal sperm. Biol. Reprod. 24, $234-240$.

Ahuja, K.K. (1985) Carbohydrate determinants involved in mammalian fertilization. Am. J. Anat. 174, 207-223.

Amann, R.P. (1987) Function of the epididymis in bulls and rams. J. Reprod. Fert., Suppl. 34, 115-131.

Arya, M. \& Vanha-Perttula, T. (1985) Lectin-binding pattern of bull testis and epididymidis. J. Androl. 6, $230-242$.

Atreja, S.K. \& Anand, S.R. (1985) Phospholipase and lysophospholipase activities of goat spermatozoa in transit from the caput to the cauda epididymidis. $J$. Reprod. Fert. 74, 687-691.

Austin, C.R. (1985) Sperm maturation in the male and female genital tracts. In Biology of Fertilization, vol. 2, pp. 121-155. Eds C. B. Metz\& A. Monroy. Academic Press, New York. 
Benga, G. (1985) Structure and Properties of Cell Membranes, Vols I-III. CRC Press, Boca Raton.

Bostwick, E.F., Bentley, M.D., Hunter, A.G. \& Hammer, R. (1980) Identification of a surface glycoprotein on porcine spermatozoa and its alteration during epididymal maturation. Biol. Reprod. 23, 161-169.

Bradley, M.P. \& Forrester, I.T. (1981) Modulation of the flagellar plasma membrane calcium pump during mammalian sperm maturation. Biol. Reprod. 24 (Suppl. 1), 42A, Abstr.

Casillas, E.R., Elder, C.M. \& Hoskins, D.D. (1980) Adenylate cyclase activity of bovine spermatozoa during maturation in the epididymis and the activation of sperm particulate adenylate cyclase by GTP and polyamines. J. Reprod. Fert. 59, 297-302.

Chakraborty, J. (1983) Monoclonal antibodies to bull sperm surface antigens. J. Cell Biol. 97, 9A, Abstr.

Courtens, J.L., Rozinek, J. \& Fournier-Delpech, S. (1982) Binding of epididymal proteins to the spermatozoa of ram. Andrologia 14, 509-514.

Crabo, B.G. (1985) Post-testicular sperm maturation and its importance to deep freezing of boar sperm. In Proc. 1st Int. Conf. Deep Freezing of Boar Semen, pp. 17-36. Eds L. A. Johnson \& K. Larsson. Swedish University of Agricultural Sciences, Uppsala.

Dacheux, J.L. \& Voglmayr, J.K. (1983) Sequence of sperm cell surface differentiation and its relationship to exogenous fluid proteins in the ram epididymis. Biol. Reprod. 29, 1033-1046.

Dacheux, J.L., Paquignon, M. \& Combarnous, Y. (1983) Head-to-head agglutination of ram and boar epididymal spermatozoa and evidence for an epididymal antagglutinin. J. Reprod. Fert. 67, 181-189.

Dacheux, J.L., Lanneau, M. \& Paquignon, M. (1984) Epididymal surface change in boar spermatozoa. Biol. Cell 51, 23A, Abstr.

Dacheux, J.L., Paquignon, M. \& Lanneau, M. (1985) Sequential analysis of the epididymal sperm maturation process in the boar. Ann. N.Y. Acad. Sci. 438, 526-529.

Devaux, P.F. \& Seigneuret, M. (1985) Specificity of lipid-protein interactions as determined by spectroscopic techniques. Biochim. Biophys. Acta 822, 63-125.

Eddy, E.M., Vernon, R.B., Muller, C.H., Hahnel, A.C. \& Fenderson, B.A. (1985) Immunodissection of sperm surface modifications during epididymal maturation. Am. J. Anat. 174, 225-237.

Fléchon, J.-E. (1981) Ultrastructural and cytochemical analysis of the plasma membrane of mammalian sperm during epididymal maturation. Prog. Reprod. Biol. 8, $90-99$

Fournier-Delpech, S. \& Courot, M. (1980) Glycoproteins of ram sperm plasma membrane. Relationship of protein having affinity for Con A to epididymal maturation. Biochem. Biophys. Res. Commun. 96, 756 761.

Fournier-Delpech, S., Courtens, J.L., Pisselet, C.L., Delaleu, B. \& Courot, M. (1983) Acquisition of zona binding by ram spermatozoa during epididymal passage, as revealed by interaction with rat oocytes. Gamete Res. 5, 403-408.

Fournier-Delpech, S., Hamamah, S., Courot, M. \& Pisselet, C. (1984) Organization of glycoproteins of sperm membrane during the development of sperm- egg recognition system into the epididymis. Biol. Cell 51, 49A, Abstr.

Fraser, L.R. (1984) Mechanisms controlling mammalian fertilization. Oxford Rev. Reprod. Biol. 6, 174-225.

Friess, A.E. \& Sinowatz, F. (1984) Con A- and WGAbinding sites on bovine epididymal spermatozoa: TEM of specimens in toto. Biol. Cell 50, 279-284.

Gagnon, C., Harbour, D., deLamirande, E., Bardin, C.W. \& Dacheux, J.-L. (1984) Sensitive assay detects protein methylesterase in spermatozoa: decrease in enzyme activity during epididymal maturation. Biol. Reprod. 30, 953-958.

Hafez, E.S.E. (1980) Reproduction in Farm Animals, 4th edn. Lea \& Febiger, Philadelphia.

Hammerstedt, R.H. (1979) Characterization of sperm surfaces using physical techniques. In The Spermatozoon, pp. 205-216. Eds D. W. Fawcett \& J. M. Bedford. Urban \& Schwarzenberg, Baltimore.

Hammerstedt, R.H. (1981) Monitoring the metabolic rate of germ cells and sperm. In Reproductive Processes and Contraception, pp. 353-389. Ed. K. W. McKerns. Plenum Press, New York.

Hammerstedt, R.H., Amann, R.P., Rucinsky, T., Morse, P.D., II, Lepock, J., Snipes, W. \& Keith, A.D. (1976) Use of spin labels and electron spin resonance spectroscopy to characterize membranes of bovine sperm: effect of butylated hydroxytoluene and cold shock. Biol. Reprod. 14, 381-397.

Hammerstedt, R.H., Keith, A.D., Boltz, R.C., Jr \& Todd, P.W. (1979a) Use of amphiphilic spin labels and whole cell isoelectric focusing to assay charge characteristics of sperm surfaces. Archs Biochem. Biophys. 194, 565-580.

Hammerstedt, R.H., Keith, A.D., Hay, S., Deluca, N. \& Amann, R.P. (1979b) Changes in ram sperm membranes during epididymal transit. Archs Biochem. Biophys. 196, 7-12.

Hammerstedt, R.H., Hay, S.R. \& Amann, R.P. (1982) Modification of ram sperm membranes during epididymal transit. Biol. Reprod. 27, 745-754.

Helmkamp, G.M., Jr (1983) Phospholipid transfer proteins and membrane fluidity. In Membrane Fluidity in Biology, vol. 2, pp. 151-185. Ed. R. C. Aloia. Academic Press, New York.

Hemminga, M.A. (1984) Interpretation of ESR and saturation transfer ESR spectra of spin labelled lipids and membranes. Chem. Phys. Lipids 32, 323-383.

Holt, W.V. (1980) Surface bound sialic-acid on ram and bull spermatozoa: deposition during epididymal transit and stability during washing. Biol. Reprod.23, $847-857$

Holt, W.V. (1982) Functional development of the mammalian sperm plasma membrane. Oxford Rev. Reprod. Biol. 4, 194-240.

Inskeep, P.B. \& Hammerstedt, R.H. (1982) Changes in metabolism of ram sperm associated with epididymal transit or induced by exogenous carnitine. Biol, Reprod. 27, 735-743.

Inskeep, P.B., Magargee, S.F. \& Hammerstedt, R.H. (1985) Alterations in motility and metabolism associated with sperm interaction with accessory sex gland fluids. Archs Biochem. Biophys. 241, 1-9.

Jauhiainen, A. \& Vanha-Perttula, T. (1986) $\beta$ - $N$-Acetylglucosaminidase in the reproductive organs and seminal plasma of the bull. J. Reprod. Fert. 76, 239-250. 
Jones, R.H. \& Molitoris, B.A. (1984) A statistical method for determining the breakpoint of two lines. Analyt. Biochem. 141, 287-290.

Keith, A.D., Sharnoff, M. \& Cohn, G.E. (1973) A summary and evaluation of spin labels used as probes for biological membrane structure. Biochim. Biophys. Acta 300, 379 419.

Koehler, J.K. (1982) The mammalian sperm surface: An overview of structure with particular reference to mouse spermatozoa. In Prospects For Sexing Mammalian Sperm, pp. 23-42. Eds R. P. Amann \& G. E. Seidel, Jr. Colorado Associated University Press, Boulder.

Koehler, J.K. (1985) Sperm membranes: segregated domains of structure and function. In Proc. 1st Int. Conf. Deep Freezing of Boar Semen, pp. 37-60. Eds L. A. Johnson \& K. Larsson. Swedish University of Agricultural Sciences, Uppsala.

Lands, W.E.M. (1980) Fluidity of membrane lipids. In Membrane Fluidity: Biophysical Techniques and Cellular Regulation, pp. 69-73. Eds M. Kates \& A. Kuskis. Humana Press, Clifton.

Loewus, M.W., Wright, R.W., Jr, Bondioli, K.R., Bedgar, D.L. \& Karl, A. (1983) Activity of myo-inositol-1phosphate synthase in the epididymal spermatozoa of rams. J. Reprod. Fert. 69, 215-220.

Low, M.G., Ferguson, M.A.J., Futerman, A.H. \& Silman, I. (1986) Covalently attached phosphatidylinositol as a hydrophobic anchor for membrane proteins. Trends Biochem. Sci. 11, 212-215.

Mann, T. \& Lutwak-Mann, C. (1981) Male Reproductive Function and Semen, pp. 195-268. Springer-Verlag, Berlin.

Marsh, D. (1981) Electron spin resonance: spin labels. In Membrane Spectroscopy, pp. 51-142. Ed. E. Grell. Springer-Verlag, New York.

Nicolson, G.L. (1982) Mammalian sperm plasma membrane. In Prospects For Sexing Mammalian Sperm, pp. 5-16. Eds R. P. Amann \& G. E. Seidel, Jr. Colorado Associated University Press, Boulder.

Nikolopoulou, M., Soucek, D.A. \& Vary, J.C. (1985) Changes in the lipid content of boar sperm plasma membranes during epididymal maturation. Biochim. Biophys. Acta 185, $486-498$.

Olson, G.E. \& Orgebin-Crist, M.-C. (1982) Sperm surface changes during epididymal maturation. Ann. N.Y. Acad. Sci. 383, 372-392.

O'Rand, M.G. (1985) Differentiation of mammalian sperm membranes. In Biology of Fertilization, vol. 2, pp. 103-120. Eds C. B. Metz \& A. Monroy. Academic Press, New York.

Parks, J.E. \& Hammerstedt, R.H. (1985) Developmental changes occurring in the lipids of ram epididymal spermatozoa plasma membrane. Biol. Reprod. 32, 653-668.

Peterson, R.N. \& Russell, L.D. (1985) The mammalian spermatozoon: a model for the study of regional specificity in plasma membrane organization and function. Tissue \& Cell 17, 769-791.

Peterson, R.N., Saxena, N.K., Saxena, N., Henry, L.H. \& Russell, L.D. (1985) Organization of the plasma membrane of boar spermatozoa: the concentration of major proteins increases markedly during maturation in the epididymis. J. Cell Biol. 101, 364A, Abstr.

Peterson, R.N., Hunt, W.P. \& Henry, L.H. (1986) Inter- action of boar spermatozoa with porcine oocytes increase in proteins with high affinity for the zona pellucida during epididymal transit. Gamete Res. 14, 57-64.

Polnaszek, C.F., Schreier, S., Butler, K.W. \& Smith, I.C.P. (1978) Analysis of the factors determining the EPR spectra of spin probes that partition between aqueous and lipid phases. J. Am. Chem. Soc. 100, 8223-8232.

Racker, E. (1985) Reconstitutions of Transporters, Receptors, and Pathological States. Academic Press, New York

Russell, L.D., Peterson, R.N., Hunt, W. \& Strack, L.E. (1984) Post testicular surface modifications and contributions of reproductive tract fluids to the surface polypeptide composition of boar spermatozoa. Biol. Reprod. 30,959-978

Saxena, N., Russell, L.D., Saxena, N.K. \& Peterson, R.N. (1984) Localization of boar sperm plasma membrane antigens at various stages of sperm maturation: do immunofluorescence results give a complete picture of antigen localization? J. Cell Biol. 99, 258A, Abstr.

Schlegel, R.A., Hammerstedt, R.H., Cofer, G.P., Kozarsky, K., Freidus, D. \& Williamson, P. (1986) Changes in the organization of the lipid bilayer of the plasma membrane during spermatogenesis and epididymal maturation. Biol. Reprod. 34, 379-391.

Schwartz, H.M. (1982) Use of electron spin resonance to study complex biological membranes. In Physical Methods on Biological Membranes and Their Model Systems, pp. 39-53. Eds F. Conti, W. E. Blumberg, J. deGier \& F. Pocchiari. Plenum Press, New York.

Sinowatz, F. \& Friess, A.E. (1983) Localization of lectin receptors of bovine epididymal spermatozoa using a colloidal gold technique. Histochemistry 79, 335-344.

Susko-Parrish, J.S., Hammerstedt, R.H. \& Senger, P.L. (1985) Binding of 125 I-succinylated concanavalin A to bovine spermatozoa. Biol. Reprod. 32, 129-136.

Suzuki, F. (1981) Changes in intramembranous particle distribution in epididymal spermatozoa of the boar. Anat. Rec. 199, 361-376.

Vierula, M. \& Rajaniemi, H. (1981) Changes in surface protein structure of bull spermatozoa during epididymal maturation. Int. J. Androl. 4, 314-320.

Vierula, M. \& Rajaniemi, H. (1982) Epididymal maturation of the surface protein structure of mammalian spermatozoa. Med. Biol. 60, 323-327.

Voglmayr, J.K., Fairbanks, G., Jackowitz, M.A. \& Colella, J.R. (1980) Post-testicular developmental changes in the ram sperm cell surface and their relationship to luminal fluid proteins of the reproductive tract. Biol. Reprod. 22, 655-667.

Voglmayr, J.K., Fairbanks, G., Vespa, D.B. \& Colella, J.R. (1982) Studies on mechanisms of surface modifications in ram spermatozoa during the final stages of differentiation. Biol. Reprod. 26, 483-500.

Voglmayr, J.K., Fairbanks, G. \& Lewis, R.G. (1983) Surface glycoprotein changes in ram spermatozoa during epididymal maturation. Biol. Reprod. 29, 767-775.

Voglmayr, J.K., Sawyer, R.F., Jr \& Dacheux, J.L. (1985) Glycoproteins: a variable factor in surface transformation of ram spermatozoa during epididymal transit. Biol. Reprod. 33, 165-176.

Wirtz, K.W.A. (1982) Phospholipid transfer proteins. In Lipid Protein Interactions, vol. 1, pp. 151-231. Eds 
P. C. Jost \& O. H. Griffith. John Wiley and Sons, New York.

Wold, F. (1986) Fatty acylation of proteins (Keep fit with fat?). Trends Biochem. Sci. 11, 58-59.

Wolf, D.E. \& Voglmayr, J.K. (1984) Diffusion and regionalization in membranes of maturing ram spermatozoa. J. Cell Biol. 98, 1678-1684.
Wolf, D.E., Hagopian, S.S., Lewis, R.G., Voglmayr, J.K. \& Fairbanks, G. (1986) Lateral regionalization and diffusion of a maturation-dependent antigen in the ram sperm plasma membrane. J. Cell Biol. 102, 1826-1831.

Zilversmit, D.B. (1983) Lipid transfer proteins: overview and applications. Methods Enzymol. 98, 565-573. 